\title{
When Do Primary Care Physicians Retire? Implications for Workforce Projections
}

\author{
Stephen M. Petterson, $P b D^{1}$ \\ William F. Rayburn, MD, MBA ${ }^{2}$ \\ Winston R. Liaw, MD, MPH ${ }^{1}$ \\ 'Robert Graham Center, Policy Studies in \\ Family Medicine and Primary Care, Wash- \\ ington, DC \\ ${ }^{2}$ Office of Continuing Medical Education \\ and Professional Development, University \\ of New Mexico School of Medicine, Albu- \\ querque, New Mexico
}

Conflicts of interest: authors report none.

\section{CORRESPONDING AUTHOR}

Stephen M. Petterson, PhD Robert Graham Center, Policy Studies in Family Medicine and Primary Care 1133 Connecticut Ave, NW, Suite 1100 Washington, DC 20036 spetterson@aafp.org

\begin{abstract}
PURPOSE Retirement of primary care physicians is a matter of increasing concern in light of physician shortages. The joint purposes of this investigation were to identify the ages when the majority of primary care physicians retire and to compare this with the retirement ages of practitioners in other specialties.
\end{abstract}

METHODS This descriptive study was based on AMA Physician Masterfile data from the most recent 5 years (2010-2014). We also compared 2008 Masterfile data with data from the National Plan and Provider Enumeration System to calculate an adjustment for upward bias in retirement ages when using the Masterfile alone. The main analysis defined retirement as leaving clinical practice. The primary outcome was construction of a retirement curve. Secondary outcomes involved comparisons of retirement interquartile ranges (IQRs) by sex and practice location across specialties.

RESULTS The 2014 Masterfile included 77,987 clinically active primary care physicians between ages 55 and 80 years. The median age of retirement from clinical activity of all primary care physicians who retired in the period from 2010 to 2014 was 64.9 years, (IQR, 61.4-68.3); the median age of retirement from any activity was 66.1 years (IQR, 62.6-69.5). However measured, retirement ages were generally similar across primary care specialties. Females had a median retirement about 1 year earlier than males. There were no substantive differences in retirement ages between rural and urban primary care physicians.

CONCLUSIONS Primary care physicians in our data tended to retire in their mid60 s. Relatively small differences across sex, practice location, and time suggest that changes in the composition of the primary care workforce will not have a remarkable impact on overall retirement rates in the near future.

Ann Fam Med 2016;14:344-349. doi: 10.1370/afm.1936.

\section{INTRODUCTION}

7 he expansion of medical school enrollment and residency programs in the 1960s through 1980s has led to more "baby boomer" physicians reaching retirement. ${ }^{1}$ This finding coincides with a minimally increasing output of physicians and an anticipated growth in demand due to a growing and aging population and to the effects of the Affordable Care Act. ${ }^{2}$ Given concerns about the shortage of primary care physicians, retirement is a matter of increasing concern. ${ }^{3,4}$

Despite its importance, physician retirement has received little attention. ${ }^{5,6}$ One difficulty is the reliance on the American Medical Association Physician Masterfile [hereafter "Masterfile"] or physicians' self-reports of their retirement intentions. Masterfile information is updated from numerous sources, including state licensing agencies, medical boards, membership organizations, and an ongoing survey. Retirement ages are inflated because of the lag in obtaining information. One study found that the Masterfile listed about 67,000 (10\%) more physicians as active than estimated by the Current Population Survey. ${ }^{7}$ Given these problems, estimates of the size of the physician workforce include some way to adjust counts downward. ${ }^{3,8}$ To correct retirement ages, recent 
studies $^{9,10}$ use estimates of retirement ages from a 2006 survey of physicians aged 50 years and older, which included retired physicians who were asked when they had retired. ${ }^{11}$ While Masterfile analyses overestimated retirement ages, self-reports of planned retirement underestimate retirement ages. ${ }^{6}$

Previously, we used National Plan and Provider Enumeration System (NPPES) data to correct for the undercount of retirees in the Masterfile. ${ }^{3,4}$ Using match rates across data sets, we calculated age-specific probabilities of being correctly classified as active in the Masterfile. This adjustment reduced our estimate of the number of active primary care physicians in 2010 by about $13,000 .{ }^{3}$ For this study, we extend this approach to adjust retirement ages.

In projections, there is considerable speculation about future retirement ages, especially as the workforce composition shifts to include higher proportions of female and urban physicians. Likewise there is concern that deteriorating work conditions in primary care have made earlier retirement more attractive. ${ }^{12}$ The purposes of this investigation were to estimate the retirement ages of primary care physicians from clinical practice and from any activity, and to determine whether retirement ages vary by sex, practice location, and specialty. This descriptive study involved nonhuman research and was exempt from approval by the University of New Mexico institutional review board.

\section{METHODS}

\section{AMA Masterfile}

The Masterfile includes data on all allopathic and osteopathic physicians, whether AMA members or not. ${ }^{13}$ It contains information about each physician's sex, primary specialty, and activity status. We pooled 2009-2014 Masterfile datasets to examine year-to-year transitions, which also allowed us to identify physicians who were dropped from the Masterfile. We provide separate results for family physicians, pediatricians, and general internists. Our designation of rural (nonmetropolitan) practice locations was based on the 2003 Rural-Urban Continuum Classification (RUCC). ${ }^{14}$

Of importance is exactly what constitutes retirement. The Masterfile uses 10 statuses: resident, direct patient care, administration, education, research, retired, semi-retired, temporarily not in practice, inactive for other reasons, and unclassified. Given policy interest in identifying physicians who will no longer provide direct patient care in the future, our main analysis identified primary care physicians as active if their status was given as direct patient care and retired if they left this status or dropped from the Masterfile.

We also estimated results based on the definition of retirement as moving from any active status to retired, semi-retired, or being dropped from the Masterfile. This second approach may be useful in estimating the number of primary care physicians needed to replace both the clinical and non-clinical workforce. ${ }^{4}$

\section{Use of NPPES Data to Correct for Upward Bias in Retirement Ages}

We matched Masterfile data with NPPES data to determine the proportion of physicians listed in the 2008 Masterfile data as in direct patient care who had obtained a National Provider Identifier (NPI) number by July 2008. We used this earlier date because the NPPES data itself does not have an effective way of identifying retirement, and in preliminary analyses, we found that most retirees continue to be listed in current NPPES data. While there is a procedure to deactivate NPI numbers, it is not enforced. To minimize this problem, we used AMA and NPPES data from July 2008, immediately after an NPI was required for most billing purposes and presumably only a small number of physicians in the NPPES had retired.

Logistic regression models were used to estimate for each specialty-age-sex-rurality group the probability of having obtained an NPI conditional on having a direct-patient-care status in the Masterfile $\left(\gamma_{t}\right)$. Based on preliminary analyses, we used a quadratic specification of age in our models.

Retirement is not the only reason AMA and NPPES data may not match. Others include the physician's not accepting insurance or working in settings that don't require an NPI to practice (such as a Veterans Administration clinic) and our not having the identifying information needed to uniquely link physicians to the NPPES. We adjusted our matched rates upward using an estimate of the proportion identified as in direct patient care in the Masterfile but not matched with the NPPES data at age 55 years.

\section{Estimation of Survival Curves}

Survival rates were calculated as follows ${ }^{15}$ :

$$
S(t)=\prod_{j \mid t_{j} \leq t}\left(\left(\frac{n_{j}-r_{i}}{n_{j}}\right) * \gamma_{t}\right)
$$

where $\gamma_{t}$ is the retirement overcount adjustment, $n j$ is the number at risk of retirement before age $t j$, and $r i$ is the number of retirees. As $\gamma_{\mathrm{t}}$ decreases with age, the likelihood of remaining active is adjusted downward. We estimated the survival of primary care physicians overall and of physicians in each primary care specialty. For purposes of comparison, we also present median retirement rates for other large specialties and subspecialties: psychiatry, obstetrics-gynecology (ob-gyn), general surgery, anesthesiology, and cardiology. 
Figure 1. Practice status of primary care physicians aged 50 to 90 years as reported in the 2014 American Medical Association Physician Masterfile.

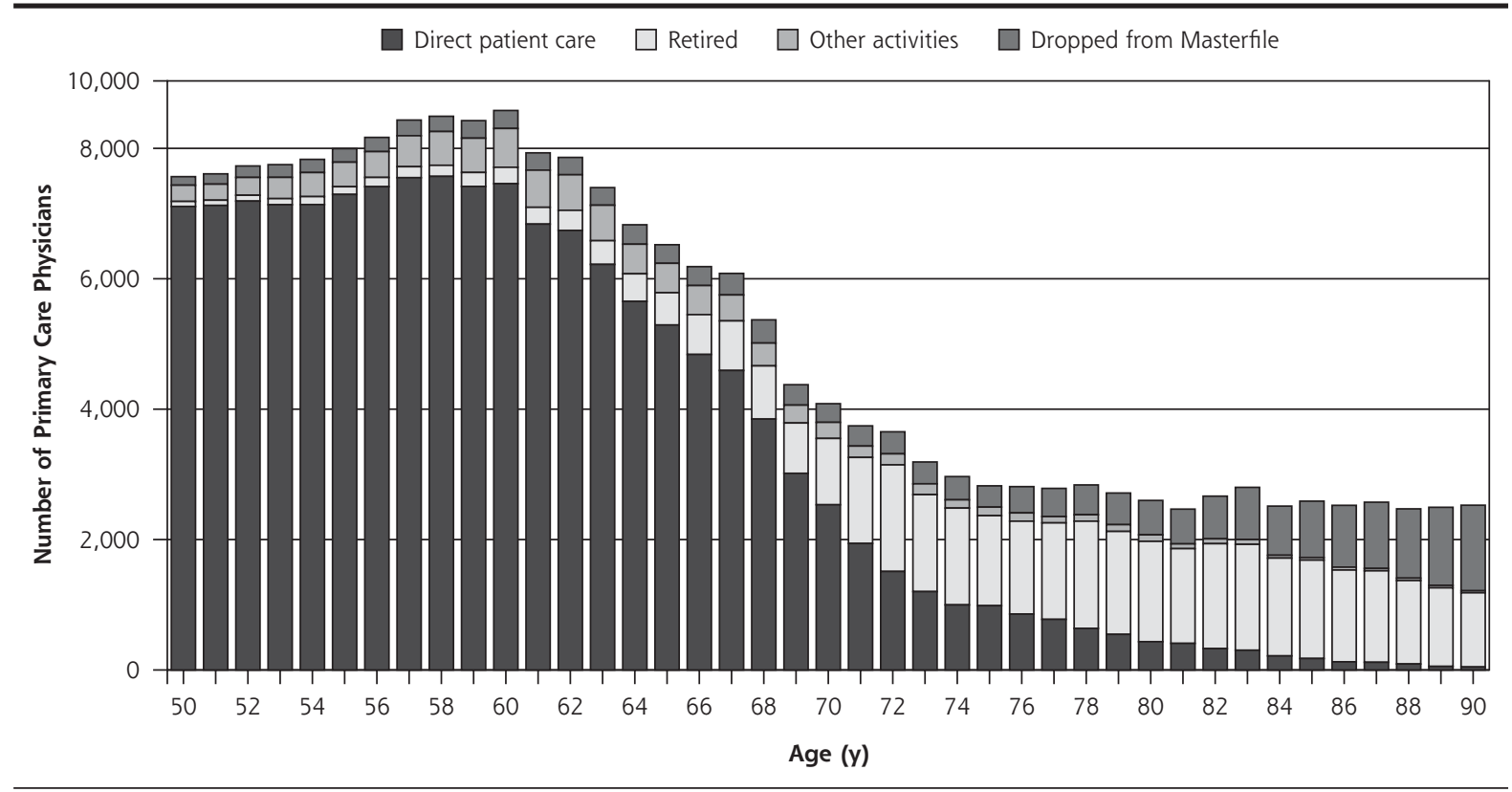

Note: The "Other Activities" category includes physicians not in clinical practice but professionally active in other ways (for example, in teaching, administration, or research); the "Dropped" category is made up of physicians who were listed in earlier years of AMA Physician Masterfile data but absent from the 2014 dataset. Data are derived from the AMA Physician Masterfile datasets for the years 2009 through $2014 . .^{13}$

\section{Statistical Analysis}

The primary outcomes were discrete Kaplan Meier survival curves used to calculate median and interquartile retirement ages across specialty, sex, location, and year. Stata 14.1 software (StataCorp LP) was used for all analyses.

\section{Estimating the Masterfile Retirement Bias}

We examined the overlap of Masterfile and NPPES data to construct a correction for the undercount of retirees in the Masterfile. The 2008 Masterfile lists 239,582 primary care physicians in direct patient care. Of these, 31,559 were not matched in the NPPES data. There was

\section{RESULTS}

\section{Practice Status by Age in the AMA Masterfile}

For context, we examined practice status for physicians aged 50 to 90 years as reported in the 2014 Masterfile (Figure 1). At age 50, nearly all primary care physicians were classified as in direct patient care or other professional activitiesadministration, teaching, or research, only 77 out of 7,566 were retired or semi-retired. The percentage retired rose slowly from $4 \%$ at age 60 years to $12 \%$ at age 65 years, then rose exponentially. An improbably high $40 \%$ of primary care physicians were still classified as being in direct patient care at age 75 years. The proportion in other non-clinical activities increased with age.

Figure 2. Percentage of primary care physicians involved in direct patient care who had a National Provider Identifier number in 2008 , by sex and age.

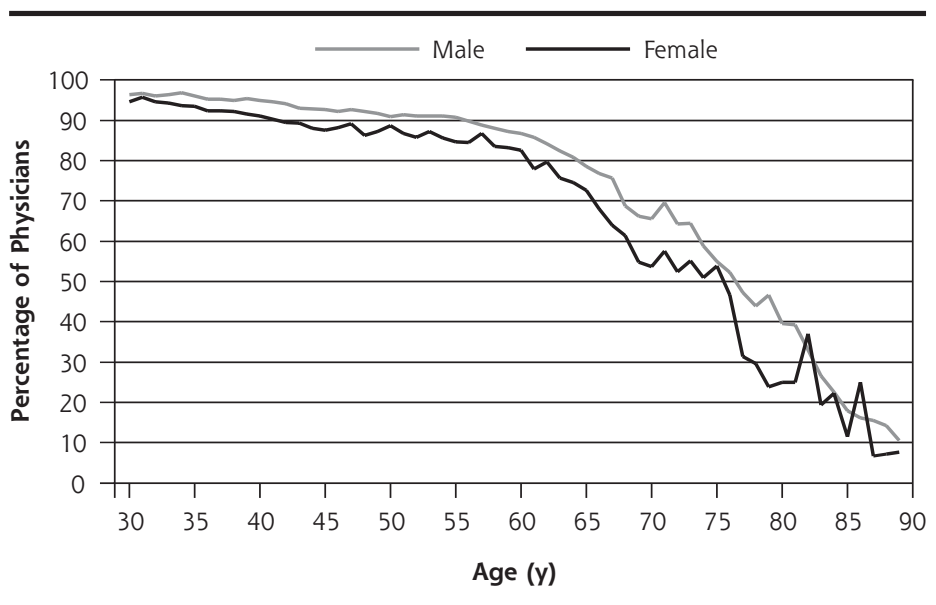

Data are derived from the AMA Physician Masterfile dataset for 2008 and from National Plan and Provider Enumeration System data for 2008. 
a nonlinear relationship between age and the percentage of physicians with an NPI number (Figure 2). The match rate initially decreases slowly-from $95 \%$ at age 30 to a little above $90 \%$ at age 55-followed by a steeper decline, reaching about $60 \%$ by age 70 and $40 \%$ by age 80. Match rates were higher for males than females.

As we said above, several factors explain why physicians listed as active in the Masterfile may not be found in the NPPES data and need to be accounted for in calculating the retirement adjustor $\left(\gamma_{t}\right)$. Approximated by the match rate of physicians at age 55 years, this value was equal to $9.9 \%$ for primary care physicians, with similar rates for each of the major primary care specialties: $8.1 \%$ for family physicians, $9.6 \%$ for general internists, and $11.5 \%$ for general pediatricians.

\section{Comparison of Retirement Ages Across Specialty and Select Characteristics}

After adjusting retirement ages, the median age when all physicians left direct patient care was 65.1 years (IQR, 61.6-68.5) and for primary care physicians was 64.9 years (IQR, 61.4-68.3; Table 1$)$. The estimates

Table 1. Median and Interquartile Range of Retirement Ages of Physicians from Either Direct Patient Care or Any Activity, By Specialty, Sex, and Practice Location, 2010-2013

\begin{tabular}{|c|c|c|c|c|c|c|c|c|}
\hline & \multicolumn{2}{|c|}{$\begin{array}{c}\text { Primary Care } \\
\text { Physicians }\end{array}$} & \multicolumn{2}{|c|}{ Family Physicians } & \multicolumn{2}{|c|}{ General Internists } & \multicolumn{2}{|c|}{$\begin{array}{c}\text { General } \\
\text { Pediatricians }\end{array}$} \\
\hline & $\mathbf{N}$ & $\begin{array}{l}\text { Median Age } \\
\text { (IQR) }\end{array}$ & $\mathbf{N}$ & $\begin{array}{c}\text { Median Age } \\
\text { (IQR) }\end{array}$ & $\mathbf{N}$ & $\begin{array}{l}\text { Median Age } \\
\text { (IQR) }\end{array}$ & $\mathbf{N}$ & $\begin{array}{c}\text { Median Age } \\
\text { (IQR) }\end{array}$ \\
\hline \multicolumn{9}{|c|}{ Retirement from direct patient care } \\
\hline All & 298,254 & $\begin{array}{c}64.9 \\
(61.4-68.3)\end{array}$ & 94,511 & $\begin{array}{c}65.1 \\
(61.6-68.4)\end{array}$ & 114,822 & $\begin{array}{c}65.6 \\
(61.8-69.3)\end{array}$ & 63,305 & $\begin{array}{c}65.7 \\
(62.1-69.1)\end{array}$ \\
\hline \multicolumn{9}{|l|}{ Sex } \\
\hline Female & 74,724 & $\begin{array}{c}64.0 \\
(60.8-67.3)\end{array}$ & 18,973 & $\begin{array}{c}64.6 \\
(61.2-67.9)\end{array}$ & 24,778 & $\begin{array}{c}64.5 \\
(61.0-68.0)\end{array}$ & 25,944 & $\begin{array}{c}64.8 \\
(61.5-68.0)\end{array}$ \\
\hline Male & 223,526 & $\begin{array}{c}65.0 \\
(61.5-68.4)\end{array}$ & 75,537 & $\begin{array}{c}65.1 \\
(61.6-68.4)\end{array}$ & 90,042 & $\begin{array}{c}65.8 \\
(62.0-69.4)\end{array}$ & 37,361 & $\begin{array}{c}66.0 \\
(62.4-69.4)\end{array}$ \\
\hline \multicolumn{9}{|c|}{ Practice location } \\
\hline Rural & 41,099 & $\begin{array}{c}65.2 \\
(61.6-68.5)\end{array}$ & 20,248 & $\begin{array}{c}65.3 \\
(61.9-68.7)\end{array}$ & 11,430 & $\begin{array}{c}66.3 \\
(62.3-69.7)\end{array}$ & 4,698 & $\begin{array}{c}66.0 \\
(62.2-69.0)\end{array}$ \\
\hline Urban & 248,825 & $\begin{array}{c}65.0 \\
(61.4-68.5)\end{array}$ & 72,934 & $\begin{array}{c}65.1 \\
(61.6-68.5)\end{array}$ & 101,205 & $\begin{array}{c}65.7 \\
(61.9-69.4)\end{array}$ & 56,660 & $\begin{array}{c}65.9 \\
(62.2-69.3)\end{array}$ \\
\hline \multicolumn{9}{|l|}{ Year } \\
\hline 2010 & 71,078 & $\begin{array}{c}64.7 \\
(61.2-68.1)\end{array}$ & 21,723 & $\begin{array}{c}64.9 \\
(61.3-68.3)\end{array}$ & 27,181 & $\begin{array}{c}65.4 \\
(61.8-69.0)\end{array}$ & 15,204 & $\begin{array}{c}65.4 \\
(61.8-68.8)\end{array}$ \\
\hline 2011 & 73,415 & $\begin{array}{c}64.9 \\
(61.4-68.3)\end{array}$ & 23,015 & $\begin{array}{c}65.2 \\
(61.7-68.6)\end{array}$ & 28,160 & $\begin{array}{c}65.8 \\
(62.0-69.3)\end{array}$ & 15,640 & $\begin{array}{c}65.6 \\
(62.1-69.0)\end{array}$ \\
\hline 2012 & 75,774 & $\begin{array}{c}65.1 \\
(61.5-68.6)\end{array}$ & 24,298 & $\begin{array}{c}65.3 \\
(61.9-69.0)\end{array}$ & 29,279 & $\begin{array}{c}65.8 \\
(61.9-69.4)\end{array}$ & 16,017 & $\begin{array}{c}66.0 \\
(62.4-69.5)\end{array}$ \\
\hline 2013 & 77,987 & $\begin{array}{c}64.7 \\
(61.2-68.2)\end{array}$ & 25,475 & $\begin{array}{c}64.8 \\
(61.5-68.0)\end{array}$ & 30,202 & $\begin{array}{c}65.4 \\
(61.5-69.2)\end{array}$ & 16,444 & $\begin{array}{c}65.9 \\
(62.2-69.2)\end{array}$ \\
\hline \multicolumn{9}{|c|}{ Retirement from any activity } \\
\hline All & 398,483 & $\begin{array}{c}66.1 \\
(62.6-69.5)\end{array}$ & 132,450 & $\begin{array}{c}66.7 \\
(63.2-70.1)\end{array}$ & 154,189 & $\begin{array}{c}67.0 \\
(63.4-70.5)\end{array}$ & 79,962 & $\begin{array}{c}66.6 \\
(63.2-70.1)\end{array}$ \\
\hline \multicolumn{9}{|l|}{ Sex } \\
\hline Female & 100,440 & $\begin{array}{c}65.2 \\
(61.9-68.5)\end{array}$ & 26,629 & $\begin{array}{c}66.2 \\
(62.7-69.8)\end{array}$ & 33,809 & $\begin{array}{c}66.0 \\
(62.5-69.5)\end{array}$ & 33,529 & $\begin{array}{c}65.7 \\
(62.4-69.0)\end{array}$ \\
\hline Male & 298,037 & $\begin{array}{c}66.2 \\
(62.7-69.6)\end{array}$ & 105,819 & $\begin{array}{c}66.7 \\
(63.2-70.1)\end{array}$ & 120,377 & $\begin{array}{c}67.0 \\
(63.5-70.5)\end{array}$ & 46,433 & $\begin{array}{c}66.9 \\
(63.4-70.3)\end{array}$ \\
\hline \multicolumn{9}{|c|}{ Practice location } \\
\hline Rural & 52,824 & $\begin{array}{c}66.4 \\
(63.0-69.7)\end{array}$ & 27,054 & $\begin{array}{c}67.0 \\
(63.6-70.3)\end{array}$ & 14,420 & $\begin{array}{c}67.4 \\
(63.9-70.7)\end{array}$ & 5,640 & $\begin{array}{c}66.8 \\
(63.4-69.9)\end{array}$ \\
\hline Urban & 333,192 & $\begin{array}{c}66.3 \\
(62.7-69.7)\end{array}$ & 102,903 & $\begin{array}{c}66.8 \\
(63.3-70.3)\end{array}$ & 136,268 & $\begin{array}{c}67.1 \\
(63.4-70.6)\end{array}$ & 71,378 & $\begin{array}{c}66.8 \\
(63.3-70.3)\end{array}$ \\
\hline \multicolumn{9}{|l|}{ Year } \\
\hline 2010 & 93,855 & $\begin{array}{c}65.8 \\
(62.4-69.2)\end{array}$ & 30,308 & $\begin{array}{c}66.5 \\
(62.9-69.8)\end{array}$ & 35,852 & $\begin{array}{c}66.6 \\
(63.1-70.1)\end{array}$ & 19,041 & $\begin{array}{c}66.4 \\
(63.0-69.7)\end{array}$ \\
\hline 2011 & 97,783 & $\begin{array}{c}66.0 \\
(62.6-69.4)\end{array}$ & 32,221 & $\begin{array}{c}66.6 \\
(63.1-69.9)\end{array}$ & 37,604 & $\begin{array}{c}66.8 \\
(63.3-70.5)\end{array}$ & 19,728 & $\begin{array}{c}66.6 \\
(63.2-70.1)\end{array}$ \\
\hline 2012 & 101,459 & $\begin{array}{c}66.3 \\
(62.7-69.7)\end{array}$ & 34,043 & $\begin{array}{c}66.9 \\
(63.4-70.4)\end{array}$ & 39,442 & $\begin{array}{c}67.1 \\
(63.5-70.6)\end{array}$ & 20,299 & $\begin{array}{c}66.8 \\
(63.2-70.2)\end{array}$ \\
\hline 2013 & 105,386 & $\begin{array}{c}66.2 \\
(62.7-69.7)\end{array}$ & 35,878 & $\begin{array}{c}66.9 \\
(63.4-70.3)\end{array}$ & 41,291 & $\begin{array}{c}67.2 \\
(63.5-70.5)\end{array}$ & 20,894 & $\begin{array}{c}66.8 \\
(63.2-70.3)\end{array}$ \\
\hline
\end{tabular}


for family physicians were close to the overall median (65.1), while those for general internists (65.6) and pediatricians (65.7) were negligibly higher. Female primary care physicians retired about 1 year earlier than males-from 0.5 year earlier for family physicians to 1.3 years earlier for general internists (Figure 3). We found only small differences in retirement ages between rural and urban physicians and no discernible trend in retirement ages from 2010 to 2013.

Using the alternative definition of retirement (retirement from any type of professional activity), retirement ages were about 1 year higher across all primary care specialties for both male and female physicians; the median was 66.1 overall (IQR, 62.6-69.5;

\section{Figure 3. Percentage of primary care physicians remaining in} practice, by age and sex.

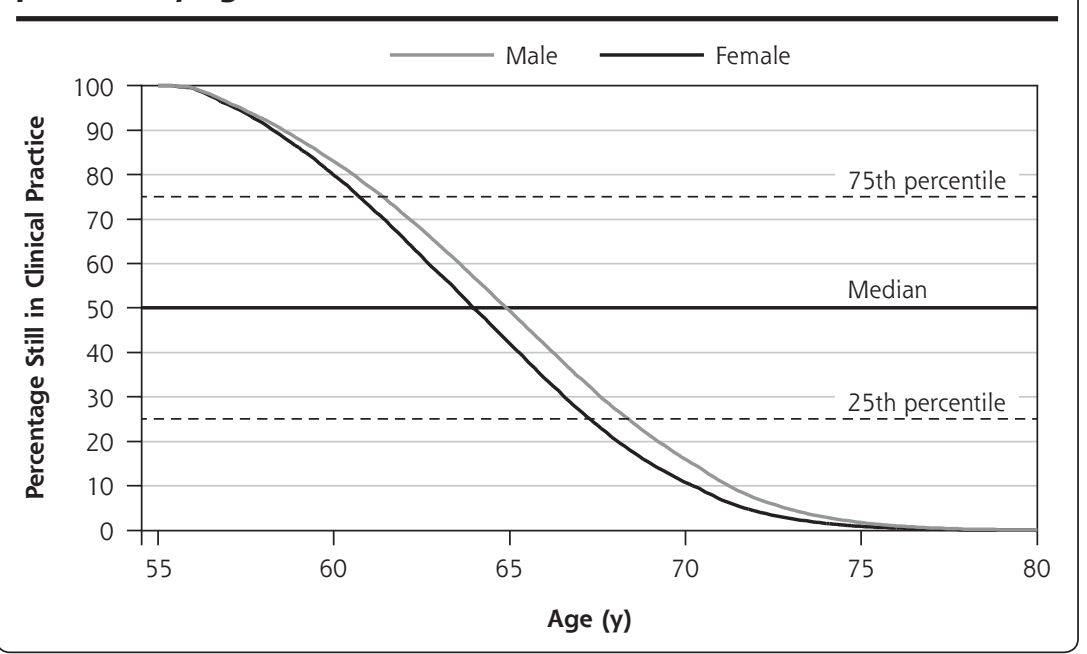

Figure 4. Median ages of retirement from clinical activity and from all professional activity for selected specialties, with interquartile ranges.

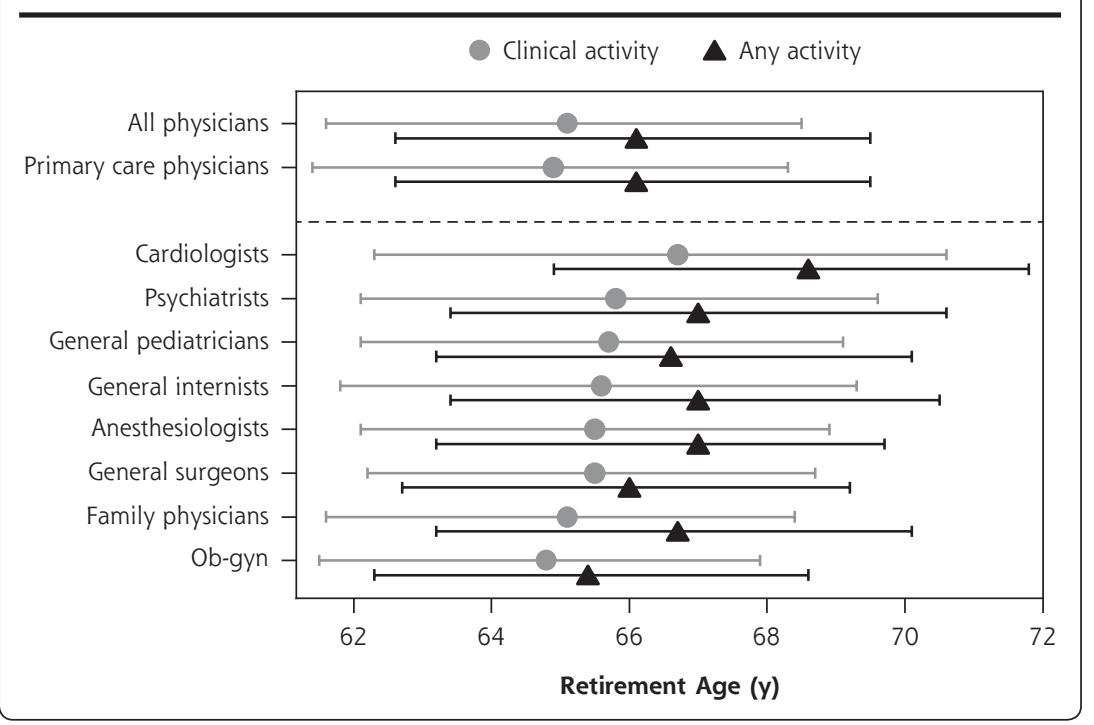

Table 1). As with retirement from clinical activity, median retirement ages across major specialties were comparable to the overall median (Figure 4). Physicians in obstetrics and gynecology had the earliest median retirement age, while cardiologists had the latest.

\section{DISCUSSION}

Most of the retired primary care physicians identified in our data retired from direct patient care in their mid-60s, with females retiring slightly earlier than males. The median age of retirement for primary care physicians was comparable to that for other specialties. A sizeable number of physicians moved from clinical practice into administrative, teaching, and research positions late in their careers.

Our findings have implications for workforce projections. For example, in our previous work ${ }^{4}$ we assumed a retirement age of 66 years, based on survey data from the Association of American Medical Colleges, ${ }^{11}$ and then projected $16 \%$ larger shortages if primary care physicians retired at age 64 years instead. This demonstrates how changes in underlying assumptions can lead to substantially different results. On the other hand, the relatively small differences in retirement ages across sex, absence of difference across location, (rural or urban), and stability in rates across time (albeit a short 5-year period), all suggest that ongoing workforce composition shifts will not have a major impact on overall retirement rates in the near future. Arguably, factors that may lower retirement ages (eg, the influx of female physicians) may be offset by other factors (eg, longer life expectancies or economic downturns).

Extending the period of clinical practice by a few years would favorably impact the shortterm shortages of physicians in primary care. Prolongation of practice may not appeal to many primary care physicians, however. Alternatives to retirement from 
medicine include working part-time, being employed in a nonclinical health setting, and substituting for another physician. ${ }^{16}$

A strength of the current investigation was our use of NPPES data to better validate when physicians retired across several specialties. We are unaware of any better means to assess retirement age in national data. A few limitations are worth mentioning. First, we did not determine whether physicians stopped seeing patients abruptly or worked part-time before retirement. Second, we could not examine how retirement ages during this 5 -year period compared with those many years ago. Future retirement ages may change in response to changes such as practice transformation and consolidation. Finally, we did not assess the retirement patterns of early and mid-career physicians. Future workforce projections will need to assess both the efforts to recruit primary care physicians and attrition among younger cohorts, some of whom have exhibited signs of burnout. ${ }^{2,17,18}$

In summary, addressing the primary care physician shortage has led us to a better understanding of the customary retirement age range. Strategies to lengthen careers would be worthwhile for policy makers to explore. Quality-of-life accommodations such as a reduction in full-time work, weekend work, or on-call requirements are important to factor into those strategies. ${ }^{19}$ Lastly, findings from this investigation will serve as a baseline for tracking the large cohort of primary care physicians approaching retirement.

To read or post commentaries in response to this article, see it online at http://www.annfammed.org/content/14/4/344.

Key words: age factors; clinical medicine; primary care physicians; primary care; retirement

Submitted December 4, 2015; submitted, revised, February 7, 2016; accepted February 17, 2016.

\section{References}

1. Salsberg E, Grover A. Physician workforce shortages: implications and issues for academic health centers and policymakers. Acad Med. 2006;81(9):782-787.

2. The Patient Protection and Affordable Care Act, 42 USC $\$ 18001$ (2010). http://housedocs. house.gov/energycommerce/ppacacon.pdf. Published May 2010.

3. Petterson SM, Liaw WR, Phillips RL Jr, Rabin DL, Meyers DS, Bazemore AW. Projecting US primary care physician workforce needs: 2010-2025. Ann Fam Med. 2012;10(6):503-509.
4. Petterson SM, Liaw WR, Tran C, Bazemore AW. Estimating the residency expansion required to avoid projected primary care physician shortages by 2035. Ann Fam Med. 2015;13(2):107-114.

5. Kletke PR. Physician workforce data: when the best is not good enough. Health Serv Res. 2004;39(5):1251-1255.

6. Rittenhouse DR, Mertz E, Keane D, Grumbach K. No exit: an evaluation of measures of physician attrition. Health Serv Res. 2004;39 (5):1571-1588.

7. Staiger DO, Auerbach DI, Buerhaus PI. Comparison of physician workforce estimates and supply projections. JAMA. 2009;302(15): 1674-1680.

8. Colwill JM, Cultice JM, Kruse RL. Will generalist physician supply meet demands of an increasing and aging population? Health Aff (Millwood). 2008;27(3):232-241.

9. Health Resources and Services Administration Bureau of Health Professions, National Center for Health Workforce Analysis. Projecting the supply and demand for primary care practitioners through 2020. http://bhpr.hrsa.gov/healthworkforce/supplydemand/usworkforce/primarycare/projectingprimarycare.pdf. Published Nov 2013.

10. Dall T, West T, Chakrabarti R, lacobucci W. The complexities of physician supply and demand: projections from 2013 to 2025. Association of American Medical Colleges. https://www.aamc.org/ download/426242/data/ihsreportdownload.pdf?cm_mmc=AAMC-_ScientificAffairs-_-PDF-_-ihsreport. Published Mar 2015.

11. Dill MJ, Salsberg ES. The complexities of physician supply and demand: projections through 2025. Association of American Medical Colleges. https://members.aamc.org/eweb/upload/The\%20Complexities\%20of\%20Physician\%20Supply.pdf. Published Nov 2008.

12. Bodenheimer T, Sinsky C. From triple to quadruple aim: care of the patient requires care of the provider. Ann Fam Med. 2014;12(6): 573-576.

13. American Medical Association. AMA physician masterfile. http:// www.ama-assn.org/ama/pub/about-ama/physician-data-resources/ physician-masterfile.page. Published 2015.

14. US Department of Agriculture. Measuring rurality: rural-urban continuum codes. http://www.ers.usda.gov/data-products/rural-urbancontinuum-codes/.aspx. Published 2004.

15. Kaplan EL, Meier P. Nonparametric Estimation from Incomplete Observations. J Am Stat Assoc. 1958;53(282):457-481.

16. Merritt, Hawkins and Associates. Survey of physicians 50 to 65 years old. http://www.merritthawkins.com/pdf/mha2007olderdocsurvey.pdf. Published 2007.

17. Rabatin J, Williams E, Baier Manwell L, Schwartz MD, Brown RL, Linzer M. Predictors and Outcomes of Burnout in Primary Care Physicians. J Prim Care Community Health. 2016;7(1):41-43.

18. DesRoches CM, Buerhaus P, Dittus RS, Donelan K. Primary care workforce shortages and career recommendations from practicing clinicians. Acad Med. 2015;90(5):671-677.

19. Keeton K, Fenner DE, Johnson TRB, Hayward RA. Predictors of physician career satisfaction, work-life balance, and burnout. Obstet Gynecol. 2007;109(4):949-955. 